\title{
Boosting Cultural Heritage in Rural Communities Through an ICT Platform: The Viv@vó Project
}

\author{
Carlos R. CUNHA, Aida CARVALHO, Luís AFONSO, Daniel SILVA, Paula Odete \\ FERNANDES, Luís Carlos PIRES, Carlos COSTA, Ricardo CORREIA, Elsa \\ RAMALHOSA, Alexandra I. CORREIA and Alexandre PARAFITA
}

Instituto Politécnico de Bragança, Campus de Santa Apolónia, Bragança, Portugal

Correspendence should be addressed to : Carlos R. CUNHA;crc@ipb.pt

Received date: 20 March 2019; Accepted date: 21 June 2019; Published date: 9 September 2019

Academic Editor : Pedro Neves Rito

Copyright (C) 2019. Carlos R. CUNHA, Aida CARVALHO, Luís AFONSO, Daniel SILVA, Paula Odete FERNANDES, Luís Carlos PIRES, Carlos COSTA, Ricardo CORREIA, Elsa RAMALHOSA, Alexandra I. CORREIA and Alexandre PARAFITA. Distributed under Creative Commons CC-BY 4.0

\begin{abstract}
Rural regions concentrate on themselves a very rich set of ancestral traditions. The perpetuation of such traditions has been achieved through transmission between generations. Unfortunately, all this knowledge is typically elders-centered and it lacks effective processes of digitalization, storage and providing-systems for that all this heritage can effectively be perpetuated through future generations that are digital-born. From this base, it was created a project case study limited to the Portuguese Northeast region, named Viv@vó - living in the grandma's house. This paper presents the ICT platform that was created in this project and some main achievements during the project development process. Tourism and mainly experience and cultural heritage tourism are growing in tourist's interests. Rural regions have an untapped potential for this slice of tourism industry. Rural regions have an enormous collection of ancestral knowledge that we are responsible to deliver to future generations as an inheritance to which they are entitled.
\end{abstract}

Keywords: Tourism, Immaterial Heritage, Rural Regions, ICT, Case Study

Introduction

Tourism is "a social, cultural and economic phenomenon which entails the movement of people to countries or places outside their usual environment for personal or business/professional purposes. These people are called visitors (which may be

Cite this Article as: Carlos R. CUNHA, Aida CARVALHO, Luís AFONSO, Daniel SILVA, Paula Odete FERNANDES, Luís Carlos PIRES, Carlos COSTA, Ricardo CORREIA, Elsa RAMALHOSA, Alexandra I. CORREIA and Alexandre PARAFITA (2019)," Boosting Cultural Heritage in Rural Communities Through an ICT Platform: The Viv@vó Project", IBIMA Business Review, Vol. 2019 (2019), Article ID 608133,

DOI: $10.5171 / 2019.608133$ 
either tourists or excursionists; residents or non residents) and tourism has to do with their activities, some of which involve tourism expenditure" (UNWTO, 2017). It's one of the greatest attractions of modern times, bringing together people, places and an interaction with different cultures. It's one of the most important economic activities for the communities and can play a decisive role in the development of the regions, especially the most demographically depressed. It is growing at a global level and Portugal has followed this trend.

Data from the Portuguese National Statistics Institute (INE) and the Bank of Portugal (BP), show that tourism increased exponentially in 2017, in all regions of the country, offering about 335 thousand jobs (more than 44 thousand than in 2016), (18\% of total shares in 2017), contributing to $7.8 \%$ of Gross Domestic Product (GDP) (INE, 2017; BP, 2017).

The Northern Region of Portugal, including the sub-regions of Porto, Minho, Douro and Trás-os-Montes, has been growing as a tourist destination. In fact, the number of overnight stays per 100 inhabitants, between 2001 and 2016, and accommodation capacity of hotel establishments, between 2009 and 2016, had a significant growth, being superior of the Portuguese average growing rate. Despite all the advantages, this can represent a risk to the consumption of natural, cultural, ethnographic, patrimonial resources, among others, (Aall, 2011; Buckley \& Araújo, 1997). Hence, there is a need for all this growth to be strategically based on the sustainability pillars of the territories, according to the principles adopted by UNWTO in 2004 . Tourism must take full account of its current and future economic, social and environmental impacts, addressing the needs of visitors, the industry, the environment and host communities. This concept incorporates three dimensions: 1) environmental (responsible use of environmental resources and conservation of heritage and biodiversity); 2) sociocultural (preserving cultural heritage, community values and promoting intercultural relations); 3) economic (contribute to alleviating poverty, and promoting socio-economic benefits for all stakeholders). In this sense, it is extremely important to promote touristic destinations in this premise, especially the North region, given the unique characteristics, offering different tourist products, to retain and attract visitors. There is currently a search for experiences authentic and contextualized as a way of escaping copies and banality (Kolar \& Zabkar, 2010; Naoi, 2004; Yeoman et al., 2007).

Tourists are looking for connections and experiences that are rooted in destination (Boyle, 2004). Among the many characteristics that generate authenticity for a destination, we can highlight the products, food and all local knowledge about their cooking (Bessière, 1998; Ray, 2000; Simpson, 2001; Hjalager e Richards, 2002; Yeoman et al., 2007). Typical dishes produced with local ingredients, with knowledge coming from traditions and shaped by the historical conditions that make each dish unique and impossible to be carried out in other regions (Bessière, 1998; Groves, 2001). However, consumers look not only for the finished product but also for all the social and cultural conditions under which the product was generated (Littrell et al., 1993).

\section{Tourism Experience}

Tourism experience is, by definition, the way in which, unlike traditional tourism, the tourist is the protagonist of the trip, experiencing the production of typical products, accompanying and / or participating in the crops, experiencing the local culture, as explained in table 
Table 1: Differences between traditional tourism and experiences tourism

\begin{tabular}{|l|l|}
\hline \multicolumn{1}{|c|}{ Traditional tourism } & \multicolumn{1}{c|}{ Experiences tourism } \\
\hline Focuses on the functional characteristics & Focuses on consumer experience \\
\hline Focuses on the product and competition & $\begin{array}{l}\text { Focuses on offering experiences in an integral } \\
\text { and exclusive way }\end{array}$ \\
\hline The consumer decisions are rational & The consumer is rational and emotional \\
\hline The tools used are quantitative and verbal & $\begin{array}{l}\text { The tools are multidisciplinary and quite } \\
\text { varied }\end{array}$ \\
\hline
\end{tabular}

Source: (Sebrae, 2015)

The concept of experience demonstrates the possibility of a unique, special, extraordinary moment that occurs during particular experiences at different moments of life. The experience happens when a company intentionally uses the "services as a stage and the products as support to attract consumers in order to create a memorable event" (Pine II \& Gilmore,
1999). This new approach reflects that the economic value of the "relationship" is not only based on customer acquisition or loyalty, but prioritizes the dimension of the experience: Entertainment, Learning, Evasion and Aesthetics. Experience is an individual event that occurs in response to a stimulus, involving five distinct phases, table 2:

Table 2: Five stimulus in an individual experience event

\begin{tabular}{|l|l|}
\hline Sense & It appeals to the senses of consumers. \\
\hline Feel & It appeals to emotions and inner feelings. \\
\hline Think & It evokes the rational side and involves consumers in cognitive experiences. \\
\hline Act & Stimulates physical behaviors, lifestyles and interactions. \\
\hline Relate & $\begin{array}{l}\text { It develops experiences that stimulate consumer desires to participate or belong to } \\
\text { a specific social or community context. }\end{array}$ \\
\hline
\end{tabular}

Source: (Schmitt, 1999)

The new tourist wishes to travel to destinations where, more than visiting and contemplating, it is also possible to feel, live, move and be a character of his own journey. Participation takes place in a commitment to co-creation, a collaboration that innovates and adds value, generating return for all stakeholders and the unique and memorable experience for tourists. "A tourism experience of co-creation is the sum of the psychological events that a tourist crosses when actively contributing through physical and / or mental participation in the activities and interacting with other subjects in the surroundings of the experience" (Campos, Mendes, Valle, \& Scott, 2016, p. 1311).

We are faced with a new paradigm because "societal changes and trends are reflected in the behavior of consumers, who are seeking more and more authentic and deep cultural tourism experiences" (Richards, 2012). The tourism of experience, also called the creative tourism, happens through the transformations and the evolution of the times, in which the interests of the tourist turn out to be more diversified and, above all; selective. The Creative tourism is "driven by experiences in co-creation, in an unforgettable and unique journey of discovery, learning and experience, revalorizes traditions and enhances the sustainability of destinations, representing an integrated, interrelated and interconnected vision between "culture itself" (Ashton et. al, 2014). 
In order to respond to the increasing demand of new and innovative ways to satisfy visitors needs before, during and after the tourism experiences, and upmost their information and easy services-access that tourists want; new Information and Communication Technologies (ICT) approaches are needed. Also, ICT can be a valuable resource to support the creation of immaterial heritage repositories, helping that the cultural human-centered knowledge can be perpetuated through future generations.

\section{Viv@vó project - living in the grandma's house case study}

The Viv@vó - living in the grandma's house case study, has been developed to generate authentic and contextualized experiences for visitors, valuing the local singularities of popular culture, human heritage and contributing to the preservation of the cultural heritage of the regions. It was developed in a rural community, in two towns located in Trás-os-Montes, a northeast region of Portugal.

The project has developed a system for surveying, selecting and disseminating the cultural heritage of the villages, allowing visitors to enjoy a contextual experience, and listening to stories while sharing a meal at their grandmother's house. The figure of the "Grandmother" appears as a guardian of the immaterial cultural heritage, a legacy holder and a connoisseur of the traditions transmitted through orality. This project presents also an important social function of aggregating and valuing the elderly as a legitimate source of knowledge, giving tourist visibility to rural areas and concomitantly contributing to the increase in income, since the grandmother earn a monetary contribution for the service provided and sale of local products.

The project also brings challenges and social functions in the fight against the isolation of grandmothers who, in this way, interact and periodically socialize with visitors. It was also one important objective of the project, one ICT platform to promote, support and disseminate the project and the visitors' needs. It was also very important that the ICT platform could create a repository with grandmother's testimonials - an immaterial heritage valuable contribution for future generation and the preservation of ancestral knowledge.

\section{Methodology}

In order to respond to the objectives defined in the project, primary and secondary sources have been used. The secondary sources served as a theoretical apportion to the ethnographic diagnosis, and the following phases were performed:

Phase 1: Theoretical and scientific framework on the ethnographic field, including a brief approach to the concepts of ethnography and its field of action. This phase included the survey of the local cuisine and gastronomy with a strong ethnographic propensity involving all the senses: touch, smell, sight, smell and taste. The idea of the experience was tried to feel, so that others can imagine the sense of the place. To do this, it was necessary to:

(a) organize and conduct interviews with local individuals who fit into the project experience;

(b) capture ethnographic testimonies, through audio visual means - image and sound - about family contexts, family and local life and their gastronomic experience, the local landscape, the social dynamics of the space and the artifacts that establish relationship with the local cuisine of Trásos-Montes.

Phase 2: Observation and analysis with the objective of identifying potential sites and individuals that fit the project. A Definition of selecting criteria for project participants. The criteria established were:

a) Residing in small rural villages and being over 60 years old.

b) Cultivating regional products and cooking traditional recipes with local ingredients and knowing the associated traditions.

c) Owning a house with adequate conditions for the reception of tourists and liking to interact with new people.

Carlos R. CUNHA, Aida CARVALHO, Luís AFONSO, Daniel SILVA, Paula Odete FERNANDES, Luís Carlos PIRES, Carlos COSTA, Ricardo CORREIA, Elsa RAMALHOSA, Alexandra I. CORREIA and Alexandre PARAFITA (2019), IBIMA Business Review, DOI: 10.5171/2019.608133 
Once the criteria were defined, the search began for potential participants. Two participants were found to serve as pilot models.

Phase 3: Implementation of tourism experience and critical analysis. The experience involved the grandmother and the communities that received the tourists confectioning regional dishes.

After this process, an ICT platform was designed and developed which combines a web based application and a mobile devices of Android application to support the digitalization of cultural heritage knowledge, promote and sell cultural services and create a regional platform of traditional cultural heritage to serve tourists/visitors demand of cultural traditional experiences.

\section{Developed ICT Platform}

In order to respond to the challenges of creating a repository of immaterial heritage human-centered knowledge implementing effective support for promotion, duringexperiences, tourists' needs, and after experiences fruition expectations, an ICT platform has been developed. The platform has two main modules: A web-based application, made to support the promotion of events and to be a knowledge repository; and mobile application developed to support the visitors' needs during the fruition of the cultural heritage experiences.

\section{Web Based Application}

We started the work with the concern of the architecture of the application where MVC (Model View Controller) technology was given more importance than programming architecture, this structure makes use of three layers providing easy handling and allowing the reuse of classes and parts of the project. The MVC is wide used in many webbased applications (S.S. Hasan \& R.K. Isaac, 2011; Veerabhadra \& Vatsavayi, 2014; Neven et. al, 2018; Lee \&Wang, 2019). The platform is defined as well as how the system components will organize.
Laravel which is a framework in PHP language for web development that uses the MVC architecture, was the choice for the implementation of the application. LARAVEL needs a Web Server running PHP5 or higher.

The servers:

- Apache, IIS, or Nginx report the message. XAMPP for Windows and Linux, MAMP for Mac OSX were used for our work environment.

- As previously stated, Laravel is written in PHP language. Version 5.6 was used, it needsat least version 7 of PHP.

- For the development of an application, it is also necessary for a database installed in the system. Laravel supports MySQL, MS SQL, SQLITE and PostgreSQL. We use the MySQL installed together with XAMPP. XAMPP is a small package with software that allows emulation of an Apache server on a personal computer and capable of processing the PHP language. As a result, from the installation of this package, we can operate as if the client (the computer that accesses the website) and the server (the computer that processes the PHP instructions and stores the database for queries) are two distinct points, although both are on the same machine.

Model-View-Controller Programming using MVC separates the application into three main parts:

\section{The Model layer}

The Model layer represents the part of your application that implements business logic. This means that it is responsible for obtaining the data by converting it into meaningful concepts for its application, as well as processing, validating, associating and any other data processing task.

At first glance, Model objects can be seen as the first layer of interaction with any database that you may be using in your application. But, in general, they represent the key concepts around which you implement your application. 
In the case of a social network, the Model layer takes care of tasks such as saving user data and relationships between friends, storing and retrieving users' photos, finding new friends for suggestions, and so on.

\section{The View layer}

A View displays a representation of the modelled data. Being separate from the Model object, you are responsible for using the information you provide to produce any presentation interface your application may require. For example, because the Model layer returns a dataset, the view can use them to display an HTML page or return the result in an XML format for others to consume. The View layer is not limited to representations of data in HTML or text format and can be used to deliver a variety of different formats depending on what you need such as videos, music, documents and any other format you can think of.

\section{The Controller layer}

The Controller layer handles user requests. It is responsible for returning an answer with the help of the Model and View layers. Controllers can be seen as managers taking care that all the resources needed to complete a task are delegated to the right workers. It waits for customer requests, verifies the validity according to the authentication and authorization rules, delegates data to be obtained or processed by the Models and selects the correct type of presentation of the data that the customer is accepting to finally delegate the work to the render layer.

The development process began with the survey of requirements where it was important to raise information and understand the demand of the project. Several meetings were held with the members involved in the project where some key words relevant to the project theme were discussed. A waiting time was agreed for those responsible for the graphic aspects such as corporate identity, visual model of the application among others. After this process, a database data-model was achieved as presented in figure 1 .

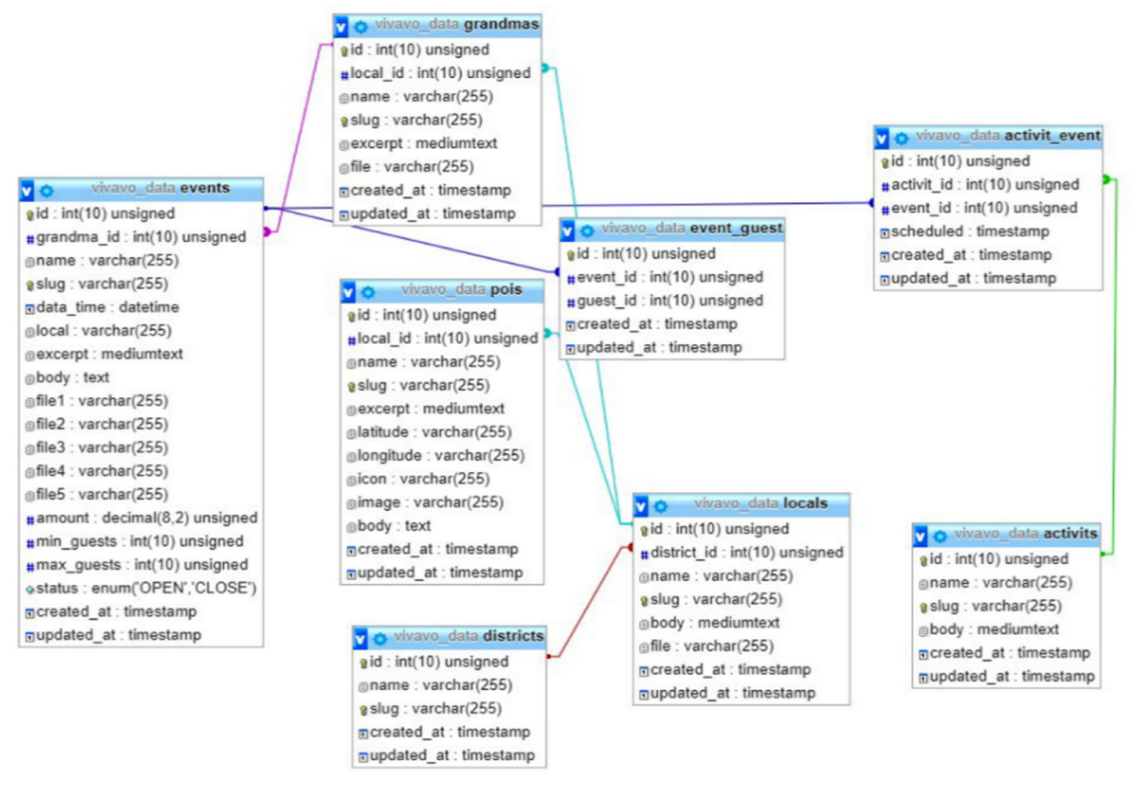

Figure 1: Database Tables, main tables, for supporting the Web application main features. 
The developed Web application have supported the promotion of the grandmother's cultural heritage offer that were materialized by cultural events in rural-natural environment. Figure 2 shows some screenshots of the developed web application.
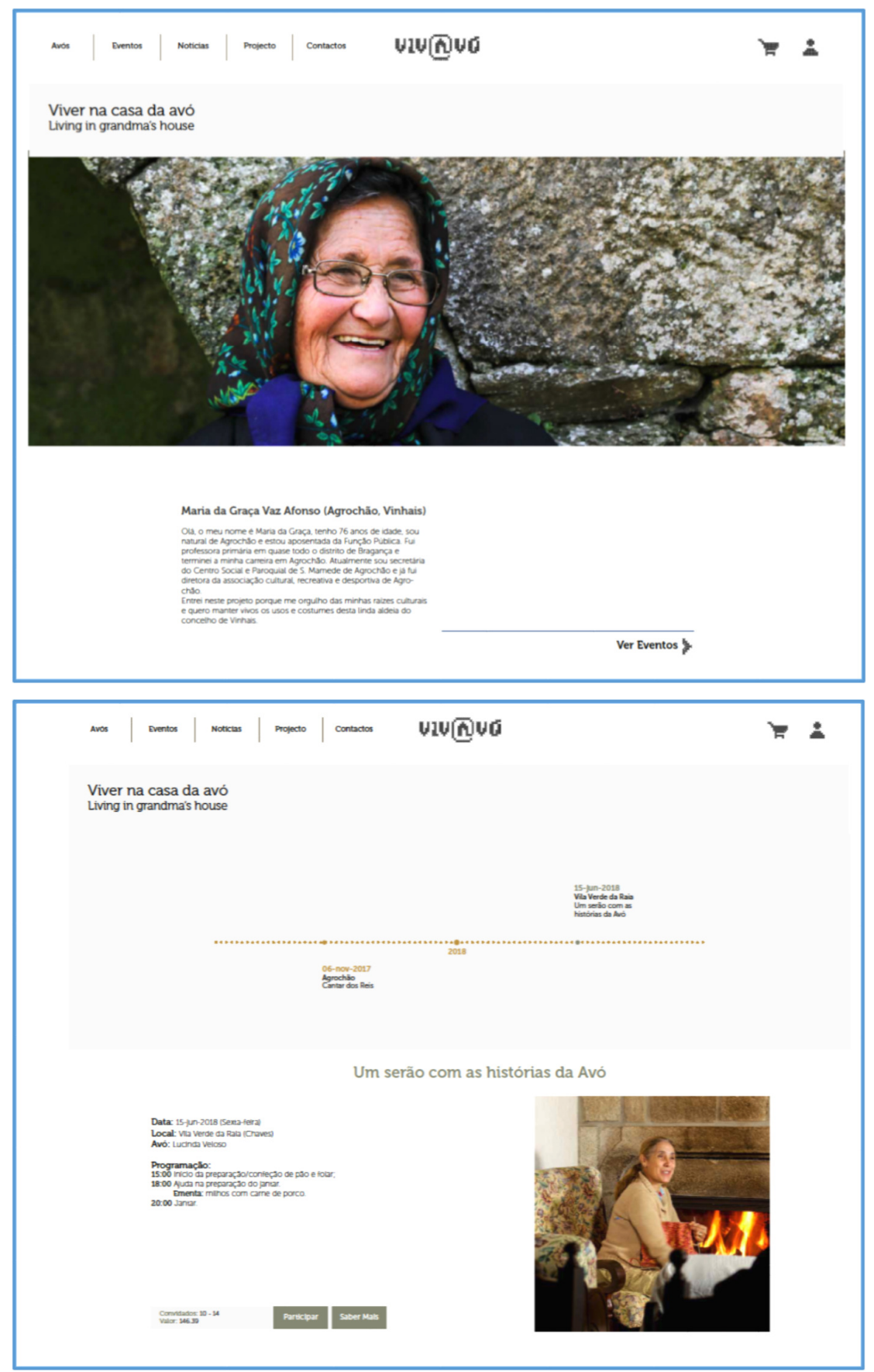

Figure 2: Web application screenshots

Carlos R. CUNHA, Aida CARVALHO, Luís AFONSO, Daniel SILVA, Paula Odete FERNANDES, Luís Carlos PIRES, Carlos COSTA, Ricardo CORREIA, Elsa RAMALHOSA, Alexandra I. CORREIA and Alexandre PARAFITA (2019), IBIMA Business Review, DOI: 10.5171/2019.608133 


\section{Mobile Device Android APP}

According to the study, a set of functionalities were defined as well as the structure of the mobile application to be developed. Among several features that have been developed, we next explain some main ones. Also a data model has been developed to support the informationfeature needs. Figure 3 shows some main database tables that exist in our database (some tables has been shared with the web application).
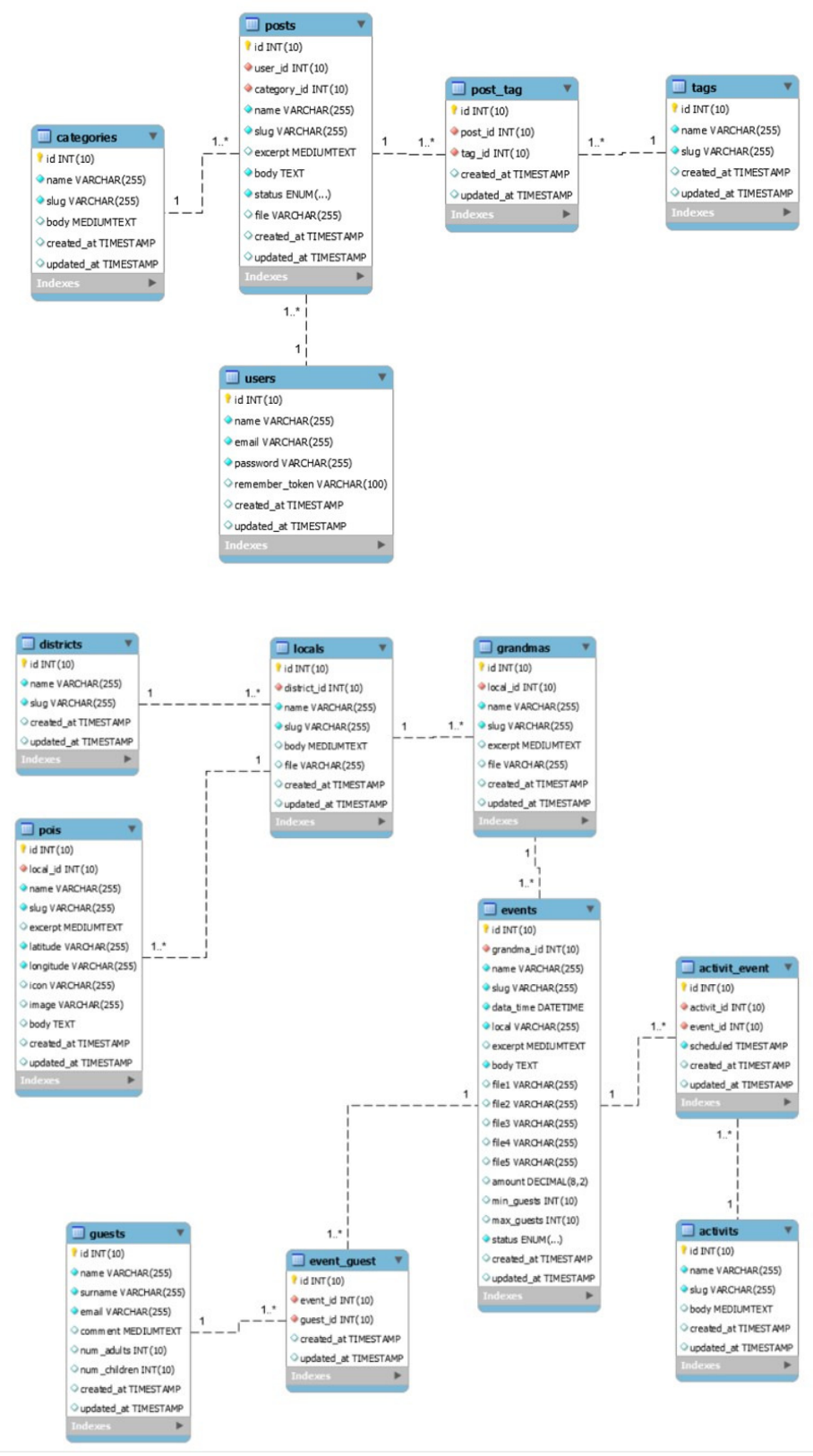

Figure 3: Some main database tables that exist in our mobile application database

Carlos R. CUNHA, Aida CARVALHO, Luís AFONSO, Daniel SILVA, Paula Odete FERNANDES, Luís Carlos PIRES, Carlos COSTA, Ricardo CORREIA, Elsa RAMALHOSA, Alexandra I. CORREIA and Alexandre PARAFITA (2019), IBIMA Business Review, DOI: 10.5171/2019.608133 


\section{Notifications}

The application sends a notification of type "push notification" so that when a user is at a distance of 1000 meters from a point of interest is warned and forwarded to that landmark on the map, obtaining detailed information about it. In the application settings, you can change the range of notifications, namely; 5000, 7000 and 10000 meters. You can also disable notifications. The user can also consult in the side menu warnings of new events that will take place, being forwarded to the details of the event and its reservation.

\section{Authentication by social network}

Users log in through their Google or Facebook account, and only after authentication can they enter the application. This was integrated into Facebook Login API in the project of Android Studio as well as Google Sign in API. These allow faster authentication without the need for registration.

\section{Event Listing}

The application lists the past and future events that will follow or be followedby a page of event details and, if it is a future event, the link to the reservation is on the project page for registration. The details screen has a gallery of the event, description and programming of the same event, future or past.

\section{Grandmother's Listing}

The application lists the grandmothers who entered the project with the name and description of each grandmother.

\section{Points of Interest}

A survey of the points of interest of the villages where the grandmothers inhabit was carried out, these coordinates are stored in the database and shown on the map. For this purpose, Google Maps API was integrated into the Android Studio project. The map has zoom tools and user location. For the user to be guided to the point he wants to visit, he is directed to Google Maps Navigation where he can navigate to the place he wants. There will also be pedestrian paths.

Figure 4 shows some screenshots of the Android mobile application that has been developed. 


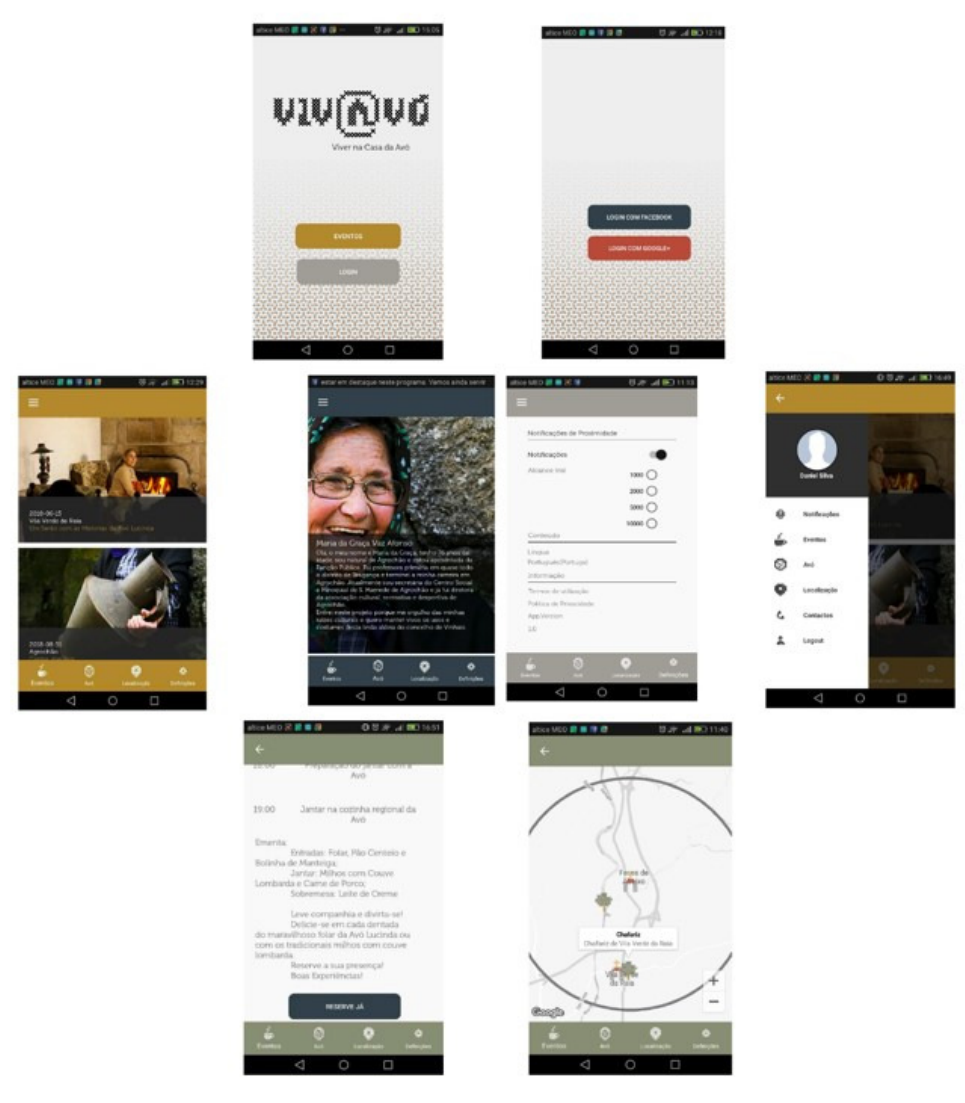

Figure 4: Android application screenshots examples

\section{Conclusion and Final Remarks}

For more than a century, there was a deep marked hermeticism between the cultural patrimony and the public, especially for expressing itself in a language that it did not dominate, and consequently, rarely expressed interest in knowing it. However, in the last decades, there was a paradigm shift that was very influenced by new tourists with the need to experiment and experience new situations. This new tourist profile requires the implementation of new communication and advertising strategies capable of capturing the attention of visitors. For this equation work, there is a greater concern of the offer-agents to adapt the interpretative discourse to the dynamics of the tourists. Also, knowing that it is of utmost importance to perpetuate the cultural heritage elders-based knowledge,

ICT can and must drive new and effective ways to promote, disseminate and democratize the access of future generations to the ancient knowledge that defines who we are and the heritage of regions and its people's traditions. The presented paper focuses mainly on the ICT component of the Viv@vó Project - Living in the Grandma's House. Its presented the developed infrastructure, both Web and Mobile applications, that have allowed supporting the digitalization and storage process of the grandma's immaterial heritage knowledge, supporting the creation and promotion of the grandma'scentered knowledge and the wide world 
promotion of a rural communities where precious's ancestral heritage exits.

\section{Acknowledgments}

The present work was developed under the Viv@vó Project: "Living in the Grandma's House", with the reference NORTE-010145-FEDER-023637, financed by the Regional Operational Program of the North, Notice 02/SAICT/2016.

\section{References}

- Campos, A. C.; Mendes, J.; Valle, P.; Scott, N. (2016). Co-Creation Experiences: Attention and Memorability. Journal of Travel \& Tourism Marketing.

- Aall, C. (2011). Energy use and leisure consumption in Norway: An analysis and reduction strategy. Journal of Sustainable Tourism, 19(6), 729-745.

- Ashton, M.S.G, E.L, Tomazzoni and M.L. Emmendoerfer (2014). Elements for the validation of crative cities as ompetitive tourist destinations. Turydes, 7 (17) 1-15.

- Bessière, J. (1998). Local Development and Heritage: Traditional Food and Cuisine as Tourist Attractions in Rural Areas, Sociologia Ruralis, 38(1), pp.21-34.

- Boyle, D. (2004). Authenticity: Brands, fakes, spin and the lust for real life, Harper Perennial, London.

- Buckley, R. C., \& Araujo, G. (1997). Environmental management performance in tourism accommodation. Annals of Tourism Research, 24, 465-469.

- BP - Banco de Portugal (2017).https://www.bportugal.pt/publicac ao/boletim-estatistico, consulted in 15-012019.

- INE - Instituto Nacional de Estatística (2017).

https://www.ine.pt/xportal/xmain?xpid=I NE\&xpgid=ine_indicadores\&indOcorrCod= $0008272 \&$ contexto $=$ bd\&selTab $=$ tab2, consulted in 17-01-2019.
- Groves, A. (2001). Authentic British food products: a review of consumer perceptions, International Journal of Consumer Studies, 25(3), pp.246-254.

- Hsien-Yu Lee, Nai-Jian Wang (2019). Cloud-based enterprise resource planning with elastic model view-controller architecture for Internet realization, Computer Standards \& Interfaces, Volume 64, pp. 11-23, ISSN 0920-5489.

- Hjalager, A. M., Richards, G. (2002). Tourism and gastronomy, Routledge, London.

- Littrell, M., Anderson, L., Brown, P. (1993). What makes a craft souvenir authentic? Annals of Tourism Research, 20, pp.197-215.

- Naoi, T. (2004). Visitors? Evaluation of a Historical District: The Roles of Authenticity and Manipulation, Tourism and Hospitality Research, 5(1), pp.45-63.

- Neven A.M. ElSayed, Ross T. Smith, Kim Marriott, Bruce H. Thomas (2018). Contextaware design pattern for situated analytics: Blended Model View Controller, Journal of Visual Languages \& Computing, Volume 44, pp. 1-12, ISSN 1045-926X.

- Pine II, B. J.; Gilmore, J. H. (1999). The experience economy: work is theatre and every business a stage. Bonton, Harvard Business School Press.

- Kolar, T., \& Zabkar, V. (2010). A consumer-based model of authenticity: An oxymoron or the foundation of cultural heritage marketing? Tourism Management, 31(5), pp.652-664.

- Ray, C., (2000). Endogenous socioeconomic development in the European Union - issues of evaluation, Journal of Rural Studies, 16(4), pp.447-458.

- Sebrae (2015). Turismo de Experiência. Recife/PE: Sebrae.

- S.S. Hasan, R.K. Isaac (2011). An integrated approach of MAS-CommonKADS, Model-View-Controller and web application optimization strategies for web- 
based expert system development, Expert Systems with Applications,Volume 38, Issue 1, pp. 417-428, ISSN 0957-4174.

- Schmitt, B. H. (1999). Experiencial Marketing: How to Get Costumers to Sense, Feel, Think, Act, Relate. New York http://cf.cdn.unwto.org/sites/all/files/doc pdf/glossaryenrev.pdf, http://sdt.unwto.org/content/about-us-5.

- Simpson, K. (2001). Strategic planning and community involvement as contributors to sustainable tourism development, Current Issues in Tourism, 4(1), pp.3-41.
- Veerabhadra Rao Chandakanna, Valli Kumari Vatsavayi (2014). A model view controller based Self-Adjusting Clustering Framework, Journal of Systems and Software, Volume 89, pp. 193-206, ISSN 0164-1212.

- UNWTO (2017). http://www2.unwto.org, consulted in 1203-2019.

- Yeoman, I., Brass, D., McMahon-Beattie, U. (2007). Current issue in tourism: The authentic tourist, Tourism Management, 28, pp.1128-1138.

Carlos R. CUNHA, Aida CARVALHO, Luís AFONSO, Daniel SILVA, Paula Odete FERNANDES, Luís Carlos PIRES, Carlos COSTA, Ricardo CORREIA, Elsa RAMALHOSA, Alexandra I. CORREIA and Alexandre PARAFITA (2019), IBIMA Business Review, DOI: 10.5171/2019.608133 